Gomes, M.M. Oliveira, C.D.M. As festas de Nossa Senhora da Conceição e a encenação da Paixão de Cristo: os desafios ao lugar do patrimônio imaterial e turístico em Pacatuba (CE). Revista Brasileira de Ecoturismo, São Paulo, v.6, n.3, ago/out-2013, pp.674-691.

\title{
As festas de Nossa Senhora da Conceição e a encenação da Paixão de Cristo: os desafios ao lugar do patrimônio imaterial e turístico em Pacatuba (CE) ${ }^{1}$
}

\begin{abstract}
The Parties of Nossa Senhora da Conceição and the play off Christ Passion: the challenges to immaterial heritage and tourism in Pacatuba city (CE, Brazil)
\end{abstract}

\section{Maryvone Moura Gomes, Christian Dennys Monteiro De Oliveira}

\section{RESUMO}

O presente trabalho objetiva discutir o lugar a partir das dinâmicas geográficas vivenciadas entre as festas de Nossa Senhora da Conceição e da Encenação da Paixão de Cristo em Pacatuba - Ceará, analisando a representação simbólica que as festas dão ao lugar, buscamos compreender de que maneira a festa espetacular desafia $\mathrm{Pa}-$ catuba enquanto bem patrimonial e turístico. Nossas análises baseiam-se em Mafesolli, Ferrara, Eliade, Di Méo, Duvignaud e Canclini, e em outros autores que trabaIham essa temática. Deste modo, a partir da abordagem cultural em geografia, bem como o relevante auxílio de outras ciências humanas a exemplo da Antropologia e Sociologia, que nos permitiram uma leitura requerida para o entendimento da espacialidade festiva. Para tanto, foi realizada pesquisa documental, observações em campo, entrevistas com organizadores e representantes da prefeitura. São os desafios da reflexão sobre a alter identidade das duas festas diante da espetacularização midiática posta, que graças a ela ou apesar dela, cabe à pesquisa evidenciar.

PALAVRAS-CHAVE: Festas; Lugar; Patrimônio; Turismo; Pacatuba (CE).

\section{ABSTRACT}

The present paper discusses the place starting from the analysis of geographical dynamics experienced by the comparison between the parties of Nossa Senhora da Conceição and the play of Passion of Christ in the city of Pacatuba - Ceará, analyzing symbolic representation that the parties give the place, we seek to understand how the spectacular party challenges Pacatuba's heritage and tourism. Our analysis is based on contributions of Mafesolli, Ferrara, Eliade, Di Meo, Duvignaud, Canclini and other authors. In this research we considered the cultural approach in geography and the assistance of other relevant social sciences like anthropology and sociology, allowed us to achieve the necessary skill for understanding the spatiality of these events. Were also performed documentary research, field observations, interviews with organizers and local authorities. The challenge on this research is the reflection on the alter identity of the two parties against the place and the "thanks to or in spite of the media spectacle" evidence being a very important view to consider.

KEYWORDS: Traditional Parties; Place; Heritage; Tourism; Pacatuba (CE, Brazil). 
As festas de Nossa Senhora da Conceição e a encenação da Paixão de Cristo: os desafios ao lugar do patrimônio imaterial e turístico em Pacatuba (CE)

\section{Introdução}

Hoje é dia de festa! A cidade se arruma, as moças se enfeitam, os rapazes se animam e a criançada se diverte. As cidades se vestem de cores, luzes e brilhos, em um palco que transforma o cotidiano em um dia especial, dia de festejar. É assim que as cidades sejam do interior ou da capital se preparam para a festa. Porém, "novas formas de viver o festejo ou a redescoberta de formas antigas para nosso mundo parecem estender o poder e o significado da festa" (grifos do autor) (BRANDÃO, 2010, p.21). E são por essas formas antigas ou novas que iremos descortinar o poder das festas de Nossa Senhora da Conceição e a Encenação da Paixão de Cristo em Pacatuba/Ce na construção do lugar enquanto espaço vivido e simbolizado.

A pesquisa intitulada As Festas de Nossa Senhora da Conceição e a Encenação da Paixão de Cristo: os desafios ao lugar do patrimônio imaterial e Turístico em Pacatuba$C E$, concentra-se em estudar o lugar em sua densidade simbólica e como a festa espetacular desafia Pacatuba enquanto bem patrimonial e turístico.

A composição da festa, o lugar simbólico, o modo como ela se espacializa, os ritos, as celebrações, as danças, as músicas, as representações, os sujeitos que participam direta e indiretamente, são elementos que estabelecem funções na sua organização e sua produção.

Desde a Idade Média, as festas se fazem presentes no cotidiano das pessoas como forma de representação da cultura popular. Era na festa de carnaval, como descreve Bakhtin em seu livro "A Cultura Popular na Idade Média e no Renascimento", sobre a obra de François Rabelais, que se tinha a abdicação provisória de todas as relações hierárquicas, de todos os privilégios, regras e tabus. Contudo, atualmente, podemos observar que as festas continuam, apesar das mudanças, sendo marcas das metrópoles brasileiras.

O ato de festejar é uma forma de extravasar, celebrar, dançar e por que não dizer de representar. A festa ocorre em um lugar único, um conjunto "especial" que tem história e significados. (TUAN, 1979, p. 387) O momento festivo é um espaço-tempo vivido e, portanto simbólico, cheio de significados e representações para quem participa da celebração.

Para Durkheim, a festa é um estado de "efervescência" que propicia a aproximação dos indivíduos, tem sua marca no júbilo e no prazer, sendo, portanto, uma dimensão transgressiva (DURKHEIM, 1912, p. 542-548 apud MAIA, 1999, p. 192-193). Já Amaral destaca que:

As festas parecem oscilar (...) entre dois pólos: a cerimônia (como forma exterior e regular de culto) e a festividade (como demonstração de alegria e regozijo). Elas podem se distinguir dos cotidianos por sua amplitude e do mero divertimento pela densidade. Na verdade, os dois elementos têm afinidades (1998, p. 38).

Contudo, é nesse estado de efervescência, delírio e oscilações, que as festas ganham importante destaque na dinâmica das cidades brasileiras, pela pluralidade de sentimentos por elas criada, como sentimentos de pertencimento, de fé e devoção, de recria- 
ção e ritualização, que fazem com que as especificidades locais sejam vistas e sentidas de forma mais explícita.

No Estado do Ceará algumas festas do ciclo natalino e junino vêm ganhando destaque no imaginário popular, na cultura e mídia, são exemplos às festas de padroeiro, folias de reis, pastoril, lapinhas, festivais juninos, entre outras. A pesquisa corresponde a investigação a respeito das festas populares do ciclo natalino e junino nos municípios de Pacatuba e Maracanaú - Região Metropolitana de Fortaleza - Ceará, Brasil, que vem ganhando forma pela apropriação dos espaços festivos, pela resistência e conservação da tradição adquirindo a condição de "espetáculos urbanos" para manter a vitalidade da tradição em um contexto pós-moderno. O presente artigo é produto do projeto de pesquisa financiado pela CAPES e Ministério da Cultura, pelo edital Pro-cultura/2009 denominado A Dimensão territorial das festas populares e do turismo: estudo comparativo do patrimônio imaterial em Goiás, Ceará e Sergipe, desenvolvido pela rede: Programa de Pós-Graduação em Geografia da UFC, Laboratório de Estudos e Pesquisas das Dinâmicas Territoriais - LABOTER e Programa de PósGraduação em Geografia do Instituto de Estudos Socioambientais da UFG e Núcleo de Pós-Graduação em Geografia da UFS.

A grande diversidade cultural do Estado do Ceará possibilita que os organizadores desses eventos utilizem como artifício para manutenção das tradições, a espetacularização, o formato de festival, a cenografia, a criação de espaços temáticos, entre outras formas também presentes nos grandes eventos festivos.

Contudo, as festas criam teias de significados tecidas pelo homem ligadas as experiências, valores, representações, mitos e ritos que expressam a identidade de um grupo, vividos no lugar. A proposta desse estudo é analisar o lugar simbólico da cidade de Pacatuba, como referência topológica dos dois ciclos festivos: "natalino" e "junino", tendo como objeto empírico de investigação a festa de Nossa Senhora da Conceição (padroeira da cidade), comemorada em 8 de dezembro, no ciclo natalino; e a Encenação da Paixão de Cristo, realizada na semana santa, antecipando o ciclo junino na abertura do ciclo pascal. Neste sentido, essa segunda festa anuncia os eventos do ciclo mais festivo, o junino, podendo por isso catalisar a força midiática que o evento tomou.

A pesquisa apresenta uma abordagem qualitativa, baseada na realização de entrevistas semiestruturadas, enquetes e relatos dos moradores, visitantes, pároco da igreja matriz e organizadores das referidas festas sobre suas experiências. Os levantamentos de campo foram feitos em dois momentos: nos meses de abril/junho e novembro/dezembro de 2011. Além de pesquisa documental em matérias de jornais digitais ( $O$ Povo e Diário do Nordeste) e sites institucionais, tomando como base as publicações nos anos de 2000 a 2010.

Esses dados serviram para a compreensão da dinâmica espacial das festas que ocorrem nos natalino e junino, considerando-se a espacialidade dos processos e sua complexidade na pós-modernidade. 
As festas de Nossa Senhora da Conceição e a encenação da Paixão de Cristo: os desafios ao lugar do patrimônio imaterial e turístico em Pacatuba (CE)

\section{As festas cíclicas na Região Metropolitana de Fortaleza}

As festas religiosas seguem o calendário litúrgico da Igreja Católica Apostólica Romana (ICAR), orientando as celebrações e ritos praticados pelos cristãos durante todo ano. O calendário é divido em Ciclo Pascal ${ }^{2}$, Ciclo Natalino ${ }^{3}$ e Tempo Comum ${ }^{4}$. As duas principais celebrações cristãs são o Natal e a páscoa, pois no Natal se celebra o nascimento de Jesus Cristo e na Páscoa sua morte e ressurreição.

Essas festas possuem grande significado para os cristãos, pois é através dos ritos festivos que o homem religioso se aproxima dos deuses. Como ressalta Eliade (2001), o mundo renova-se anualmente, isto é, reencontra a cada ano a santidade original, tal como quando saiu das mãos do Criador. As festas religiosas são de grande significado para os cristãos, pois é na festa através dos ritos que o homem religioso se aproxima dos deuses.

Como atividade para compreendermos as festas religiosas e de calendário, consideramos analisar as dinâmicas das festas cíclicas (juninas e natalinas) no Estado do Ceará proposto pelo Projeto Pró-Cultura. Concomitantemente aos levantamentos de campo, também construímos o banco de dados das festas populares do Estado do Ceará, produto do Projeto Pró-Cultura, a partir de pesquisa documental em matérias de jornais digitais, conforme já foi mencionado. O banco de dados vem servindo de apoio à composição de tabelas e para as análises das festas cadastradas nesse estudo. O Quadro 1 sintetiza as características gerais das festas nos ciclos natalino e junino.

Quadro 1: Características das festas do ciclo natalino e junino.

Table 1: Characteristics of feasts of the cycle Christmas and "junino".

\begin{tabular}{|c|c|}
\hline \multicolumn{2}{|c|}{ Características Gerais das Festas Cíclicas na RMF/Ceará } \\
\hline CICLO NATALINO & CICLO JUNINO \\
\hline Festas que remetem aos santos do ciclo; & Festas que remetem aos santos do ciclo; \\
\hline $\begin{array}{c}\text { Período de comemoração ao nascimento } \\
\text { de Jesus Cristo, momento de mudanças e } \\
\text { renovação; }\end{array}$ & Festa da colheita; \\
\hline $\begin{array}{c}\text { Presença mítica forte; } \\
\text { Apresentação de danças folclóricas; }\end{array}$ & Danças, trajes típicos, e culinária própria do \\
período;
\end{tabular}

Fonte: Jornais O Povo e Diário do Nordeste. Organizado por Maryvone M. Gomes, Nov/ 2011. Source: Journals "O Povo" and "Diário do Nordeste". Organized by Maryvone M.Gomes, Nov/2011. 
Analisando o quadro acima, notadamente se destacam as festas em homenagem aos santos em ambos os ciclos. As danças, trajes e comidas típicas marcam os dois ciclos, assim como os rituais festivos e os símbolos. É no momento da festa que a identidade cultural de um grupo torna-se mais visível, na medida em que o ambiente simbólico da festa estrutura a paisagem enquanto um sistema de significados (COSTA, 2010).

O Calendário litúrgico da ICAR cobre todo o ano litúrgico, com passagens, acontecimentos bíblicos e em especial duas grandes celebrações: o natal e a páscoa, são os momentos vivenciados mais intensamente pelo cristão. As festas do ciclo natalino fazem referência a uma das principais celebrações cristãs, o nascimento de Jesus Cristo. As festividades desse ciclo iniciam em 24 de dezembro e finaliza-se no dia 07 de janeiro com festa do Batismo do Senhor, pelo calendário cristão. O Natal é uma data simbólica, uma convenção da cristandade, que representa o nascimento de Jesus Cristo para os cristãos. Diz a tradição, que o dia 25 de dezembro foi adotado para que a data coincidisse com a festividade romana dedicada ao "nascimento do deus sol, que comemorava o solstício de inverno", em cultos pagãos. A data era tida também como o do nascimento do deus persa Mitra, o Sol da Virtude.

Alguns estudiosos dizem que a Igreja, no século IV, tornou muitas datas de festas pagãs em festas cristãs como forma de conversão cada vez maior de povos pagãos ao cristianismo. Os festejos desse ciclo remetem as festas de padroeiros, Epifania, Festa do Divino Espírito Santo, Folias de Reis e Pastoril. Em algumas regiões do Estado o ciclo se estende até fevereiro com a festa de Nossa Senhora das Candeias. Com o caminhar dos levantamentos das festas cíclicas, constatamos que estas não se situam estaticamente em um determinado ciclo, mas transbordam para outros ciclos ou transitam entre os ciclos festivos obedecendo à necessidade dos que a produzem. Elas permitem a maleabilidade das localidades em trabalhar a espetacularização dos eventos, conforme seu poder de oferta para atender as demandas crescentes.

Algumas festas desse ciclo vêm ganhando destaque no imaginário popular, na cultura e mídia. No Estado do Ceará, as festas nesse período celebram os autos de Natal, lapinhas e os presépios, são acompanhados de danças como pastoril e reisados. Segue abaixo quadro das atividades de campo das festas do ciclo natalino realizada pela equipe Pró-Cultura Ceará referente à 2010/2011. Nos levantamentos de campo realizados no ciclo natalino, destacamos a forte presença mítica presentes nas festas de padroeiros, reisados e lapinhas (Quadro 2).

Podemos notar em alguns locais pesquisados a presença de muitos fieis nas festas religiosas natalinas, porém nem os novos atrativos incorporados às festas, nem os apelos espetaculares com estruturas exuberantes, conseguiram atrair o turista para alguns das festas realizadas nesse período. O que sinaliza que a construção de espetáculos para festividades tradicionais nas cidades metropolitanas não rompe com o processo de invisibilidade do evento, dificultando assim uma gestão integrada com o turismo. Concluímos que o turista não é atraído apenas pela festa, mas também pelo conjunto de atrativos oferecidos pela localidade. 
As festas de Nossa Senhora da Conceição e a encenação da Paixão de Cristo: os desafios ao lugar do patrimônio imaterial e turístico em Pacatuba (CE)

Quadro 2: calendário de atividades de campo - ciclo natalino.

Table 2: schedule of field activities - Christmas Cycle.

\begin{tabular}{|r|c|c|}
\hline \multicolumn{2}{|c|}{ Pesquisa de campo - Ciclo Natalino - Equipe Ceará Pró-Cultura } \\
\hline FESTA & LOCAL & DATA \\
\hline Nossa Senhora da Conceição & Pacatuba - CE & $03 / 12 / 10$ à 08/12/10 \\
\hline Nossa Senhora da Conceição & Messejana - Fortaleza/CE & $08 / 12 / 10$ \\
\hline Festa de Santa Luzia & Meireles - Fortaleza/CE & $13 / 12 / 10$ \\
\hline Pastoril & Dragão do Mar - Fortaleza/CE & $18 / 12 / 10$ \\
\hline Natal de Brilho & Maracanaú - CE & $21 / 12 / 10$ \\
\hline Folias de Reis, lapinhas e reisados & Juazeiro e Crato/CE & $04 / 01 / 11$ à 08/01/11 \\
\hline Festa de São Sebastião & Goiabeiras - Fortaleza/CE & $20 / 01 / 11$ \\
\hline
\end{tabular}

Fonte: Projeto Pró-cultura Ceará. Organizado por Maryvone M. Gomes, Jan/2011.

Source: Pró-cultura Ceará Project. Organized by Maryvone M. Gomes, Jan/2011.

As festas do ciclo junino representam a mudança de estação climática e o início do ciclo da fartura ou colheita. Momento de celebração e agradecimento pela colheita, em que muitos relembram as suas origens, através das danças, das comidas típicas e dos rituais. Como confirma (Lévi-Strauss, 1983), "a comemoração é à volta as origens e consequentemente a consciência da História". As festas juninas procuram referenciar três santos católicos: Santo Antônio, São João Batista e São Pedro.

Em Fortaleza muitos são os bairros que celebram as festas de São João ${ }^{5}$, e que acabaram deixando o formato de "festa para brincar quadrilha" e passaram para o formato competitivo dos festivais e arraiás. Algumas das festas distribuídas por Fortaleza destacam-se pelos festivais tradicionais de quadrilhas, como o Arraiá da Cumade Chica no bairro José Walter, Vila São João no bairro Conjunto Ceará, Arraiá do Cumpadre Rogério no bairro Amadeu Furtado, Festival de Quadrilhas do Grande Bom Jardim no bairro Bom Jardim, Festival de Quadrilhas do Bairro Ellery no bairro Ellery, Festival São Mateus no bairro Nossa Senhora das Graças, Arraiá do Cumpadre Kiko no bairro Monte Castelo, entre outras festas.

Para entender como as festas nos municípios da região metropolitana, se mantêm visível diante da diversidade cultural do Estado é importante penetrarmos na temática da "tradição inventada" de Eric Hobsbawm (1984), que sintetiza:

Por "tradição inventada" entende-se um conjunto de práticas, normalmente reguladas por regras tácita ou abertamente aceitas; tais práticas, de natureza ritual ou simbólica, visam inculcar certos valores e normas de comportamento através da repetição, o que implica, automaticamente; uma continuidade em relação ao passado. 
Consideramos aqui tanto as "tradições" institucionalizadas, na perspectiva do patrimônio cultural, quanto as que são reconhecidas popularmente assim, mesmo sem um longo período de tempo para cristalizá-las. Nesse sentido a invenção de tradições é essencialmente um processo de formalização e ritualização caracteriza-se por referir ao passado, mesmo que apenas pela imposição da repetição. (HOBBAWM; RANGER, 1984)

As tradições antes rígidas tornam-se obsoletas diante da modernização das técnicas, e pela incapacidade de adaptar-se deu origem às "novas" tradições. Certeau em sua obra - A Invenção do Cotidiano (1994), mostra que "o homem ordinário" inventa o cotidiano escapando silenciosamente a essa conformação da racionalidade técnica, com práticas culturais contemporâneas, recuperando as astúcias anônimas das artes de fazer numa sociedade de consumo.

Já Canclini (1989), que também aborda essa perspectiva, sugere a reformulação do "popular" constituído por processos híbridos e a modernização das práticas. O autor acredita que o objeto "puro" e "autêntico" não garante a reprodução e o benefício local. Concordamos com Canclini, pois nas observações de campo das festas pesquisadas, formas criativas foram incorporadas a festa na tentativa de um retorno positivo para a comunidade local, e nessa perspectiva as encenações ganharam novos espaços e se multiplicaram na busca por novas identidades.

Os levantamentos de campo do ciclo junino também privilegiaram as festas em Fortaleza, RMF e algumas cidades do interior do Estado, nos meses de junho e julho de 2011 (Quadro 3).

Quadro 3: calendário de atividades de campo - ciclo junino.

Table 3: schedule of field activities - "Junino" Cycle.

\begin{tabular}{|l|c|c|}
\hline \multicolumn{2}{|c|}{ Pesquisa do Ciclo Junino - Equipe Ceará Pró-Cultura } \\
\hline \multicolumn{1}{|c|}{ FESTA } & LOCAL & DATA \\
\hline Festival Junino & $\begin{array}{c}\text { Conjunto Ceará - Fortaleza/ } \\
\text { CE }\end{array}$ & $\begin{array}{c}04 / 06,17 / 06 \text { e } \\
22 / 06 / 11\end{array}$ \\
\hline Festa do Pau da Bandeira & Barbalha/CE & 12 e $13 / 06 / 2011$ \\
\hline Arraiá da Cumade Chica & José Valter - Fortaleza/CE & $25 / 06 / 11$ \\
\hline Festa de São Pedro & Mucuripe- Fortaleza/CE & $29 / 06 / 11$ \\
\hline $\begin{array}{l}\text { Festival de Quadrilhas do Cumpade } \\
\text { Rogério }\end{array}$ & Parque Araxá - Fortaleza/CE & $29 / 06 / 11$ \\
\hline São João de Maracanaú & Maracanaú/CE & $04 / 07$ e 13- \\
& & $107 / 2011$ \\
\hline Festa de Nossa Senhora do Carmo & Centro - Fortaleza/CE & $11 / 07$ e 16/07/11 \\
\hline Festa de Sant'Ana & Jaguaruana/CE & 15 A 18/07/11 \\
\hline $\begin{array}{l}\text { Festa do Centenário de Juazeiro - } \\
\text { Romaria }\end{array}$ & Juazeiro do Norte/CE & $20 / 07 / 11$ \\
\hline
\end{tabular}

Fonte: Jornais O Povo e Diário do Nordeste. Organizado por Maryvone M. Gomes, Ago/ 2011. Source: Journals "O Povo" and "Diário do Nordeste". Organized by Maryvone M.Gomes, Aug/2011. 
Nos levantamentos de campo do ciclo junino é notória a intensa atividade festiva junina em todo ciclo e por todo Estado do Ceará. Algumas festas aqui cadastradas, apesar de estarem localizadas no período do ciclo junino, não possuem nenhuma ligação direta com a tradição junina. São exemplos as festas das padroeiras Nossa Senhora do Carmo e Sant'Ana, e a homenagem ao Centenário de Juazeiro.

Das festas juninas nos terreiros aos festivais de quadrilhas mais estilizados, esses eventos mudam o cotidiano das cidades metropolitanas, especialmente nordestinas, que nesse período festejam os santos juninos. A incorporação de novas técnicas de produção e de grandes estruturas nesses eventos é uma preocupação dos organizadores na perspectiva de torná-los mais atrativos para o turista.

\section{A festa de Nossa Senhora da Conceição em Pacatuba (CE)}

Os lugares festivos estabelecem as relações simbólicas e de valores culturais, constituindo a identidade e o sentimento de pertença de um indivíduo ou um grupo. É através das relações vivenciadas no lugar simbólico das festas de Nossa Senhora da Conceição, que iremos compreender a construção das identidades dos lugares e das identidades das pessoas (ROSENDAHL, 2005).

O espaço pensado como "lugar festivo" permite entender o sentido de lugar e do evento festivo, que para Ferreira (2003) é definido pelos discursos sobre suas significações e os valores simbólicos de quem faz a festa. Desta maneira, o lugar festivo se constitui como uma instituição discursiva que, através das narrativas trazidas pelos os envolvidos nesses festejos, define uma maneira de se conceber o patrimônio de um lugar.

A investigação da construção simbólica desses lugares possibilitou a aproximação do objeto de estudo aqui proposto enquanto festa popular e a construção patrimonial do lugar, que vem ganhando importante destaque nas dinâmicas das cidades metropolitanas. E mesmo as festas que acontecem nas cidades no entorno dos grandes centros urbanos, marcam presença pela pluralidade de sentimentos por elas criada, como sentimento de pertencimento, fé, devoção, recriação e ritualização, permitindo que as especificidades locais sejam vistas e sentidas de forma mais aparente.

O lugar festivo se assemelha o que seria um "espaço de celebração"6 proposto por Maffesoli, quando o autor trata esses espaços como

[...] lugares e espaços de socialidade, mistura de afetos e de emoções comuns, consolidados pelo cimento cultural ou espiritual, em suma, existem por e para as tribos que neles escolheram seu domicílio (MAFFESOLI, 2004, p.59).

Esses espaços possuem um forte componente estético, de contemplação, de teatralização e do lúdico, onde o conjunto que delimita o imaginário social. É o conjunto que 
faz da cidade o "altar" privilegiado da estética integrada (MAFFESOLI, 2004, p.74). O espaço de celebração se confunde com a própria festa, pelo culto a estética e pela forma lúdica de festejar desde sua origem, e se multiplicam pelas cidades, como celebração ao corpo, a imagem, a amizade, a comida, entre outros.

O município de Pacatuba (Figura 1) festeja há 141 anos sua padroeira, momento muito esperado pelos pacatubanos durante todo ano. Os festejos iniciam no dia 28 de Novembro e transcorre até o dia 08 de Dezembro. A data coincide com o ano de sua emancipação política, antes pertencente à Maranguape. A igreja matriz de Pacatuba localiza-se na sede de Pacatuba, próximo de órgãos da administração municipal, da Praça Francisco das Chagas Albuquerque - popularmente conhecida como Praça da Matriz e da Praça da Paixão. E considerada como ponto de referência, tanto cartográfica pela centralidade, como pela beleza exuberante, pois fica na subida da Serra da Aratanha e do balneário das Andréa compondo uma paisagem singular.

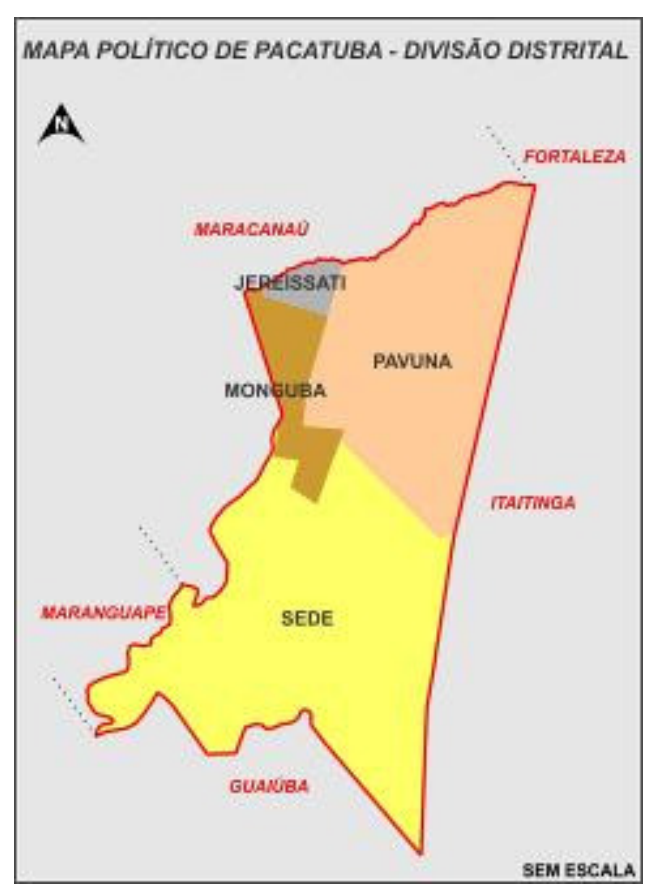

Figura 1: Mapa de divisão política de Pacatuba (CE). Fonte: IBGE. Organizado por Maryvone M. Gomes, Abril/2011.

Figure 1: Map of the political division of Pacatuba (CE). Source: IBGE. Organized by Maryvone M. Gomes, April/2011.

As festas de padroeiros assim como outras festas religiosas ocorrem em um tempo sagrado, momento vivido pelo homem religioso, como destaca Eliade (2001, p.64):

[...] A cada festa periódica reencontra-se o mesmo tempo sagrado aquele que se manifesta na festa do ano precedente ou na festa de há um século: é o tempo criado e santificado pelos deuses por ocasião de suas gestas que são justamente reatualizadas pela festa 
As festas de Nossa Senhora da Conceição e a encenação da Paixão de Cristo: os desafios ao lugar do patrimônio imaterial e turístico em Pacatuba (CE)

Neste reencontro do tempo sagrado nas festas de padroeiros, o devoto ratifica sua promessa e se sente mais próximo do seu "santo", através dos rituais próprios do momento, como novenas, procissões e missas que reatualizam a fé do povo.

Durante a festa o cotidiano da cidade é transformado em espaço festivo incorporando novas práticas. A tranquilidade de Pacatuba é quebrada nos dias da festa, em especial a festa da padroeira. A movimentação começa uma semana antes da festa da padroeira, quando começa a novena, todas as noites os religiosos se reúnem na igreja para a celebração. A novena atrai tanto moradores de Pacatuba, como de municípios vizinhos, em sua maioria, idosos. O comercio é aquecido nesse período com a montagem de barracas no entorno da Praça da igreja para venda de produtos artesanais, religiosos, comidas típicas e entretenimento em geral. Sobre a relação entre festa e espaço, Maia conclui que:

Grande parte das festas, no seu momento de ocorrência, simplesmente fornece nova função às formas espaciais prévias que dispõem para a realização (ponto central e entorno): ruas, praças, terrenos baldios, estádios de futebol transformam-se em palcos para o evento (MAIA, 1999, p. 204).

O cortejo percorre desde a entrada da cidade até a igreja matriz (Figuras 2 e 3 ), durante percurso louvores e rezas convidam os moradores para a celebração. A praça, que no cotidiano do lugar é espaço de encontro dos cidadãos de Pacatuba, nesse momento torna-se um lugar do grande espetáculo. Efeitos de som, iluminação, teatralização, ritualização do evento fizeram com que os festejos em homenagem a padroeira de Pacatuba adquirissem condição de "espetáculos".
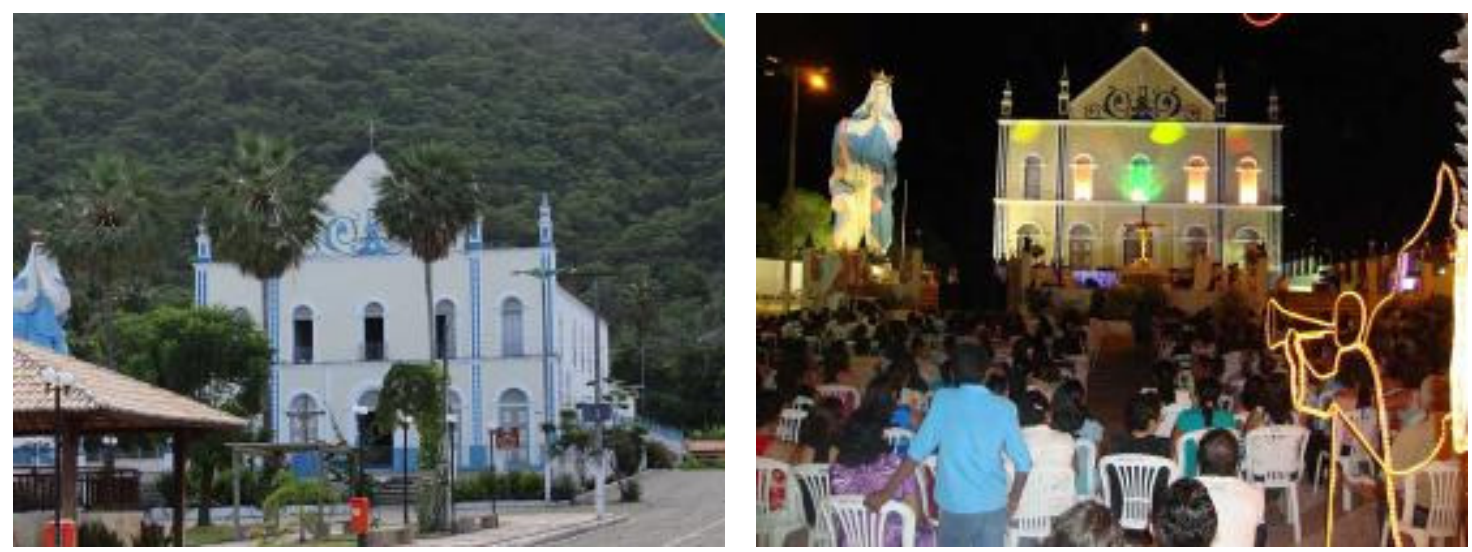

Figuras 2 e 3: igreja de Nossa Senhora da Conceição.

Fonte: Acervo de Maryvone M. Gomes, 2010.

Figures 2 and 3: Church of Nossa Senhora da Conceição.

Source: Collection of Maryvone M. Gomes, 2010. 
Dentro dessa perspectiva da realidade das festas que adquiriram formato de espetáculos, Trigueiro (2005) nos lembra com muita propriedade, "a espetacularização das culturas populares não é uma coisa tão nova como se pensa, a mudança é nos métodos de produção, na velocidade da distribuição e no mercado de consumo desses bens culturais". A mudança é gradativa, a partir das novas invenções incorporadas a esses espaços culturais.

A espetacularização das festas aqui apresentadas pode ser considerada como forma de se fazerem presentes diante das realidades festivas, gerando possivelmente uma demanda de turismo e lazer ao lugar. Porém, detectamos nas observações de campo, que a maior parte de participantes da festa de Nossa Senhora da Conceição são moradores da sede de Pacatuba ou dos distritos. Poucos registros de visitantes dos municípios vizinhos.

Essa realidade das festas cíclicas que se estabelece nos ambientes metropolitanos, e sugerem esse formato de espetáculo com tal refinamento, merecem maior aprofundamento do conhecimento científico das espacialidades festivas.

\section{A Festa da Paixão de Cristo em Pacatuba}

O espetáculo da Paixão de Cristo encenado há 38 anos é pioneiro em encenações dessa natureza no Ceará. O evento teve origem em 1974, quando o Padre Edilson encenou a Via Sacra pelas ruas da cidade, com o objetivo de movimentar a cidade. A igreja encontrou uma forma criativa de aproximar-se do povo, sobretudo contar a vida de Cristo em forma de espetáculo, promovendo assim interações entre a igreja e o povo, ou seja, entre o templo-mundo. Como bem dizia Maia (2010, p. 90 e 91) em suas pesquisas e observações,

[...] temos notado que essa ressantificação do mundo na sua totalidade é bastante expressiva em dias de festa, quando se promovem interações espaciais ritualizadas "templo-mundo" e vivenciadas com emoção, permitindo-nos demolir fronteiras tão prontas entre espaço sagrado e profano.

As doze estações foram encenadas utilizando de quadros colocados nas residências, e o Cristo acompanhava o Padre nas estações da via Sacra até a igreja. Dois anos após a criação da Via Sacra, o Sr. Antony Fernandes artista plástico e morador de Pacatuba, decidiu ajudar na produção. E pediu ao pároco que levasse os quadros para dentro da igreja, para que ele pudesse fazer um teatro mais abrangente, um trabalho diferente ${ }^{7}$.

Nesse momento a igreja perde espaço na realização da Via Sacra, deixando de realiza-la, passando essa competência ao Sr. Antony com o apoio da Prefeitura de Pacatuba. A igreja continuou com a programação religiosa na Semana Santa, mas deixou de participar mais efetivamente da encenação da Paixão de Cristo.

Cabe ratificar que a encenação da Paixão de Cristo em Pacatuba é uma festa 
de referencial religioso, não eminente católica, pois é aberta a qualquer religião. Porém é religiosa na sua forma de encenar a vida de Cristo e de passar uma mensagem cristã, e não religiosa na substância, por ser um espetáculo teatral na pressa de constitui-se como festa moderna, atendendo as necessidades dos produtores.

Nesse sentido, algumas festas cíclicas extravasam ou antecipam seu ciclo festivo, favorecidas pela flexibilidade com que as festas transitam pelos ciclos. $\mathrm{O}$ exemplo disso à encenação da Paixão de Cristo em Pacatuba, que adquiriu formato e técnica de grande espetáculo, e guiado pela força midiática, reposicionou no calendário festivo no sentido da antecipação do ciclo junino. Esse "Junino" do seu lugar se justifica por uma antecipação, dada pela força midiática, que o evento da paixão tomou. É a festa que introduz o ciclo junino nos circuito das grandes festas desse ciclo.

$\mathrm{Na}$ tentativa de reinventar o Sr. Antony Fernandes teve a ideia de encenar de forma criativa a via sacra em 1976. O idealizador montou a Via Sacra de forma artesanal, utilizando de material que dispunha e contando com a colaboração dos moradores que serviam de atores para encenar pelas ruas da cidade de Pacatuba. O cortejo saía da Igreja Nossa Senhora do Carmo seguindo pelas ruas da cidade, encenando doze passagens utilizando como cenário as frentes das residências. "A gente pedia que os donos das casas cedessem às frentes para que nós pudéssemos colocar as cortinas, uma coisa, um jarro de planta", declaração do Sr. Antony em entrevista ao site da prefeitura de Pacatuba.

No espetáculo da Paixão de Cristo que encena uma passagem religiosa, o sagrado e o profano estão imbricados. Como bem diz Cavalcante (2009) é uma profanidade que espetaculariza o sagrado, sem dessacralizá-lo. Ambas as encenações teatrais procuram a cada edição tornarem-se mais profissionais na produção desse espetáculo, mantendo o sagrado nas cenas do espetáculo que remetem a vida de Cristo.

Com o passar dos anos o aumento no público foi progressivo. Grande parte do público era proveniente do entorno de Pacatuba e de parentes que retornavam à cidade natal durante semana santa. A comunicação através da "propaganda de boca em boca" ajudou na divulgação da encenação e atraiu curiosos de diversas localidades. O percurso longo e cansativo, fez com que a população reivindicasse aos organizadores que a Via Sacra fosse para um espaço fixo, com acomodações e infraestrutura adequadas.

Foi construída a Praça da Paixão estrategicamente posicionada no epicentro das atividades sociais e importantes equipamentos da sede do município: a igreja de Nossa Senhora da Conceição, Praça da igreja matriz e sede da prefeitura (Figuras 4 e 5).

A Praça é utilizada quase exclusivamente para o espetáculo da Paixão de Cristo, o que denota sua importância na construção da identidade com o lugar e a carga simbólica para o reconhecimento do espetáculo e visibilidade de Pacatuba. O espaço da Praça da Paixão é subutilizado no restante do ano, com eventos esporádicos religiosos ou não. Existe interesse dos gestores municipais em transformar o espaço da Praça da Paixão em museu, caso o espetáculo seja transferido para outro espaço. 


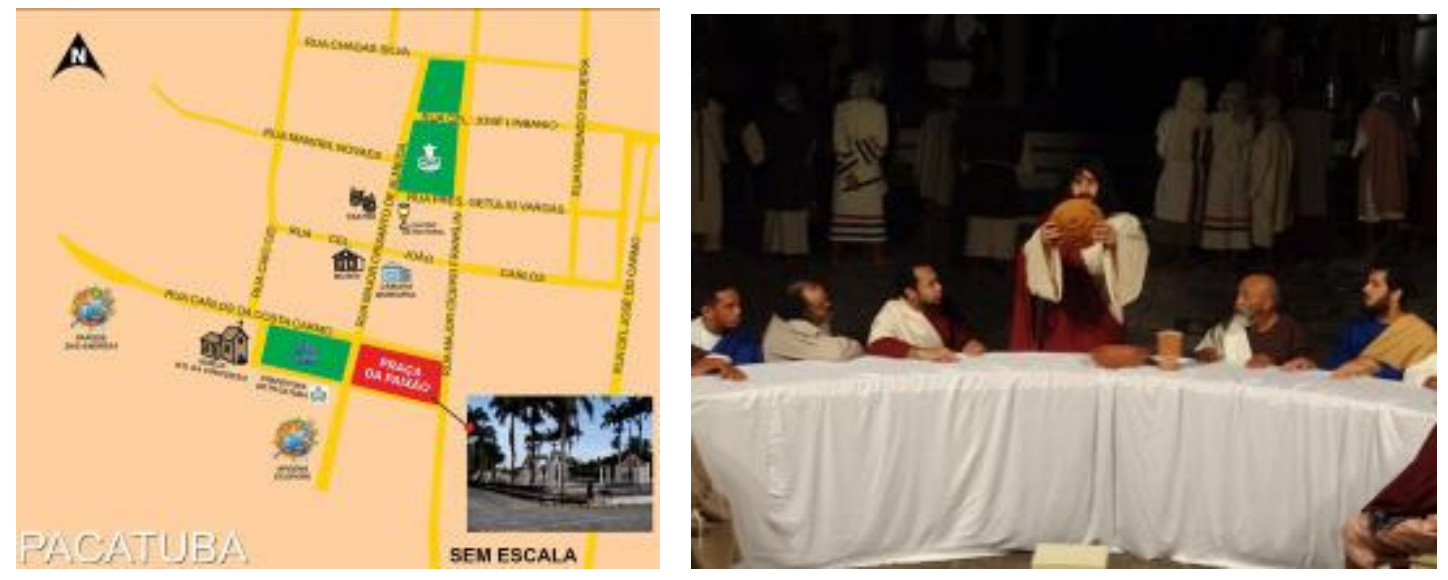

Figuras 4 e 5: localização e cena da paixão de cristo 2011.

Fonte: Google Earth 2011. Organizado por Gláumer F. de Sousa e Maryvone M. Gomes, 2012.

Figures 4 and 5: location and scene from the Passion of Christ in 2011.

Source: Google Earth 2011. Organized by Gláumer F. de Sousa and Maryvone M. Gomes, 2012

Quando pensamos a Encenação da Paixão de Cristo em Pacatuba como lugar, consideramos não só as materialidades, mas também as imaterialidades através da representação simbólica que compõem o cenário e revelam a dimensão do vivido durante aquele tempo sagrado (COSTA, 2001, p 29). As manifestações culturais, representada nesse estudo pela festa, irão construir a identidade do lugar, onde o habitante se reconhece como parte integrante do lugar. O sentimento de pertença está relacionado à aproximação e à ligação com o local de origem. É o sentimento de enraizamento, em que o indivíduo constrói e é construído, planeja e se sente parte de um projeto, modifica e é por ele modificado.

O espetáculo produzido com grande aparato técnico exigiu da Prefeitura Municipal de Pacatuba mais verba para manter grandiosa estrutura. Assim foi criada a Organização da Sociedade Civil de Interesse Público - OSCIP ${ }^{8}$ Serra da Paixão permitindo que as doações realizadas por empresas possam ser descontadas no imposto de renda.

O Ponto de Cultura foi implantado em $2008 \mathrm{com}$ a finalidade de capacitar os atores para a encenação da Paixão de Cristo, para filmes ou outros espetáculos. O ponto de cultura faz parte de um programa do Ministério da Cultura - MAIS CULTURA, que prevê repasse de $R \$ 180.000$ aos contemplados com o edital em até três anos. Em entrevista (16 de abril de 2011) com o vice-presidente da Secretaria de Turismo e Cultura, Luiz Emanuel Pereira Monteiro declarou: "O programa vem fortalecer o que já existe, essa é a filosofia do programa, surgiu da necessidade de capacitar os atores que já participavam da Paixão de Cristo e que não tinham nenhuma capacitação". O espetáculo atualmente conta com 200 pessoas entre atores e figurantes. Ao todo são 300 pessoas entre técnicos de montagem, luz e som, apoio, produção, montagem, bilheteria, segurança, equipe médica, produzindo em torno de 200 empregos informais indiretos.

A Secretaria de Turismo e Cultura de Pacatuba financia a maior parte dos gas- 
tos na produção do espetáculo, a iniciativa privada entra com uma pequena parcela $\mathrm{e}$ a própria SECULT com outra parcela via folha estadual da Cultura. No espetáculo de 2011 foi gasto pela Prefeitura de Pacatuba em torno de 200 mil reais para a realização de dois dias de evento, e contou ainda com doações de empresas instaladas no município, sem auxilio da Lei Rouanet ${ }^{9}$. Conforme entrevista com Emanuel Monteiro vice-presidente da Secretaria de Turismo e Cultura:

[...]Nunca conseguimos captar ajuda para o espetáculo via Lei Rouanet. A lei Rouanet permite que o empresário decida o que ele quer apoiar, então o empresário apoia o que para a marca deles é rentável. O espetáculo da Paixão não tem atores globais, nem grandes nomes, que façam também com que as empresas se motivem. Não tem o oIhar comercial, apenas artístico.

Nesse sentido o poder político na figura da prefeitura e do Estado via SECULT, é vista como instituição gestora desses recursos de maior competência do que os agentes de mercado, e aposta no que pode dar retorno mais imediato.

A incorporação de novas técnicas de produção e de grandes estruturas nesses eventos é uma preocupação dos organizadores na perspectiva de torná-los mais atrativos para o visitante e assim poder proporcionar para a cidade uma maior visibilidade.

Essas duas festas são exemplos de festas metropolitanas espetaculares dentre tantas outras que se modernizaram na busca de atender interesses midiáticos, políticos e econômicos. Notadamente, o formato espetacular dessas festas não proporciona uma significativa demanda de turismo, possivelmente devido a proximidade de $\mathrm{Pa}$ catuba com o município de Fortaleza, ou por razão do calendário do evento não dispor de outras opções de lazer. São suposições levantadas em campo que cabe pesquisa mais apurada para elucidar.

\section{Algumas conclusões}

O quadro que se observa na análise das festas locais, na abertura de seus respectivos ciclos (natalino e pascal/junino) aponta para a condição de "espetáculo urbano" em evolução. A dinâmica festiva das tradições cristãs modernizadas produz um campo de forças predominantemente de natureza mítica (religiosa) na festas de N. S. da Conceição e midiática (mídia) na Encenação da Paixão de Cristo, estabelecendo assim um confronto dos aspectos simbólicos com diferentes interesses políticos e econômicos.

As festas estudadas são exemplos de festas metropolitanas espetaculares que se modernizaram na busca de atender interesses midiáticos, políticos e econômicos, predominantemente. As imagens e os discursos capturados nessa primeira fase demonstram, a título de conclusão, que a construção de espetáculos para festividades tradicionais metropolitanas não rompe o processo de invisibilidade relativa dos eventos. O que dificulta assim uma gestão integrada do turismo e um desafio efetivo no 
desenvolvimento da educação patrimonial, com ênfase nos bens imateriais, notadamente os eventos festivos.

A título de colaboração com o aprofundamento da discussão em novas oportunidades de estudo, o fortalecimento dessa visibilidade deve passar por um conjunto de sugestões mais articuladas na escala metropolitana; seja na divulgação cultural, seja na interiorização do turismo regional cearense. Tendo em vista o enfoque propositivo destacamos preliminarmente quatro sugestões desse conjunto:

- A divulgação dos demais eventos festivos de Pacatuba, (Festa da Padroeira, festival de quadrilhas juninas, Saberes e Sabores, carnaval, etc.) durante a realização da Paixão de Cristo, promovendo o marketing turístico mais integrado;

- A composição de acordos com o setor de transporte para visitas à Serra da Aratanha e Trilhas ecológicas, Roteiro histórico, proporcionando também a integração das dimensões cultural e natural/ambiental;

- A gestão de uma política de encontro interestadual, considerando outros municípios no Estado que possuem encenação da Paixão e podem ajustar parcerias no aperfeiçoamento do evento;

- O incentivo a rede educacional para que o modelo de encenação possa acolher outros "autos" (manifestações da teatralização popular) ao longo do ano, inclusive com temáticas do ciclo natalino iniciadas na festa da padroeira.

Essas foram algumas proposições levantadas nesse estudo para um futuro aprofundamento nas discussões sobre as festas e as relações simbólicas, políticas, econômicas e turísticas tecidas em Pacatuba/Ceará.

\section{Referências bibliográficas}

AMARAL, R.C.M.P. Festa à Brasileira: significados do Festejar no país que não é sério. Tese de Doutoramento em antropologia. Departamento de Antropologia da Faculdade de Filosofia, Letras e Ciências Humanas - USP, 1998.

BAKHTIN, M. A cultura popular na Idade Média e Renascimento: o contexto de Rabelais. São Paulo: UCITEC, 1987.

BRANDÃO, C.R. Prece e folia: festa e romaria. Aparecida, SP: Idéias \& Letras, 2010.

CANCLINI, N.G. Culturas Híbridas: Estratégias para entrar e sair da modernidade. São Paulo: EDUSP, 1989.

CAVALCANTE, T.V.; OLIVEIRA, C.D.M. Entre o Cosmos e o Caos: A Dinâmica do Santuário Metropolitano de Fátima em Fortaleza - CE. Anais... XII Encontro de Geógrafos da América Latina - EGAL, 2009, Montevidéu. XII Encontro de Geógrafos da América Latina - Caminando en una América Latina en transformación. Montevidéu: Imprenta Gega, 2009. p. 124-124. 
As festas de Nossa Senhora da Conceição e a encenação da Paixão de Cristo: os desafios ao lugar do patrimônio imaterial e turístico em Pacatuba (CE)

CERTEAU, M. A invenção do cotidiano: 1, Artes de fazer. Petrópolis: Vozes, 1994.

CLAVAL, P. A geografia cultural. Florianópolis: Editora da UFSC, 1999.

CLAVAL, P. As abordagens da geografia cultural. In: CASTRO, I.E. et al. (orgs). Explorações geográficas: percursos no fim do século. Rio de Janeiro: Bertrand Brasil, 1997.

COSTA, O.J.L. Região e Paisagem: a sacralidade da natureza no sertão central do Ceará. Revista Espaço e Cultura. Rio de Janeiro: UERJ, no 28, p. 48, 2010.

COSTA, O.J.L. Hierópolis: o significado dos lugares sagrados do sertão cearense. In: ROSENDAHL, Z. (org). Geografia cultural: Trilhas do Sagrado. Rio de Janeiro: EdUERJ, 2010, p. 35-60.

COSTA, O.J.L. Icó: patrimônio cultural no semi-árido cearense. Propostas Alternativas: Memória e Patrimônio Cultural do Ceará - I, IMOPEC. Fortaleza, 2001.

DEL PRIORE, M. Festas e Utopias no Brasil Colonial. São Paulo: Brasiliense, 2000.

DI MÉO, G. La Geógraphie en fête. Paris: Ed. Geophrys, 2001.

DUVIGNAUD, J. Festas e Civilizações. Fortaleza: Universidade Federal do Ceará, 1983, p. 236.

ELIADE, M. O sagrado e o profano: A essência das religiões. São Paulo: Martins Fontes, 2001.

FERREIRA, L.F. O lugar festivo: a festa como essência espaço-temporal do lugar. Espaço e Cultura, Rio de Janeiro, v. 15, p. 7-21, jan./jun. 2003.

GOMES, P.C.C. Cenários para a Geografia: Sobre a espacialidade das imagens e suas significações. In: ROSENDAHL, Z.; CORRÊA, R.L. (Org.). Espaço e Cultura: pluralidade temática. Rio de Janeiro: EDUERJ, 2008

HOBSBAWM, E.; RANGER, T. A invenção das tradições. Rio de Janeiro: Paz e Terra, 1984, p. 9-23.

LÉVI-STRAUSS, C. O pensamento selvagem. São Paulo: Nacional, 1976.

MAIA, C.E.S. Ritual e emoção nas interações espaciais: repensando o espaço sagrado nas festas populares de romarias e folguedos (notas introdutórias). In:. ROSENDAHL, Z. (org.). Trilhas do Sagrado. Rio de Janeiro, EDUERJ, 2010.

MAIA, C.E.S. Ensaio interpretativo da dimensão espacial das festas populares: Proposições sobre festas brasileiras. In: ROSENDAHL, Z. (org.). Manifestações da cultura no espaço. Rio de Janeiro: EDUERJ, 1999, p. 191-218.

MAFFESOLI, M. Notas sobre a pós-modernidade: O lugar faz o elo. Rio de Janeiro: Ed. Atlântica, 2004.

MORIN, E. As Culturas de Massas no século XX: Neurose. Rio de Janeiro: Forense Universitária. 2002.

OLIVEIRA, C.D.M. Desafios contemporâneos das cidades-santuários no Estado do Ceará (Brasil): políticas patrimoniais e diocesanas. Geosaberes, Fortaleza, v. 1, n. 1, p. 37-51, maio/2010a. 
OLIVEIRA, C.D. et al. Festas Populares Religiosas e suas Dinâmicas Espaciais. REVISTA Mercator, ano 06, número 11, 2007, p. 25 - 26.

OLIVEIRA, C.D. Geografia do Turismo na Cultura Carnavalesca: O Sambódromo do Anhembi. São Paulo: Paulistana, 2007.

RAHDE, M.B.F. Considerações sobre uma estética contemporânea. Revista da Associação Nacional dos Programas de Pós-Graduação em Comunicação. Abril de 2007.

ROSENDAHL, Z. (Orgs.). Geografia: temas sobre cultura e espaço. Rio de Janeiro: EdUERJ, 2005.

SOUSA, G.F. Mapa de localização da Praça da Paixão equipamentos urbanos em Pacatuba (CE). Fortaleza, 2012. Sem escala.

TRIGUEIRO, M.O. Seminário Nacional de Políticas para a Cultura Popular. Painel: Culturas Populares, Circuitos de Difusão de Mercados, 2005.

TUAN, Yi-Fu. Space and Place: Humanistic Perspective. In: GALE, S.; OLSSON, G. (eds.). Philosophy in Geography. Dordrecht, Reidel Publ. Co., p. 387 - 427, 1979.

\section{Notas:}

${ }^{1} \mathrm{O}$ presente artigo é produto do projeto de pesquisa financiado pela CAPES e pelo Ministério da Cultura, através do edital Pró-Cultura/2009, intitulado "A Dimensão territorial das festas populares e do turismo: estudo comparativo do patrimônio imaterial em Goiás, Ceará e Sergipe", desenvolvido pela rede: Programa de Pós-Graduação em Geografia da UFC, Laboratório de Estudos e Pesquisas das Dinâmicas Territoriais - LABOTER e Programa de Pós-Graduação em Geografia do Instituto de Estudos Sócio-Ambientais da UFG e Núcleo de Pós-Graduação em Geografia da UFS.

${ }^{2}$ O Ciclo da Páscoa ou Pascal divide-se em Quaresma, Semana Santa e Tempo Pascal. O tempo pascal momento da Festa da Páscoa ou da Ressurreição do Senhor, se estende por cinquenta dias entre o domingo de Páscoa e o de Pentecostes, comemorando a volta de Cristo ao Pai na Ascensão, e o envio do Espírito Santo. Disponível em: <http:// catholicum.wikia.com/wiki/Ano_litúrgico>. Acesso em: 20 de outubro de 2011.

${ }^{3}$ O Ciclo do Natal ou Natalino se divide em Advento e Tempo do Natal. Nesse ciclo são celebradas as festas da Sagrada Família, de Maria, mãe de Jesus e do Batismo de Jesus. O Tempo do Advento é o momento de preparação para a vinda de Cristo, iniciam-se quatro domingos antes do Natal e termina no dia 24 de Dezembro, desembocando na comemoração do nascimento de Cristo. Esse tempo cristão vai da véspera do Natal de Nosso Senhor até o domingo depois da festa da Epifania, em que se comemora o Batismo de Jesus. Disponível em: <http://catholicum.wikia.com/wiki/Ano_litúrgico>. Acesso em: 20 de outubro de 2011.

${ }^{4} \mathrm{O}$ Tempo Comum é um período sem grandes acontecimentos para a igreja católica, é o momento que a igreja chama de acolhimento da palavra de Deus. Disponível em: <http:// catholicum.wikia.com/wiki/Ano_litúrgico>. Acesso em: 20 de outubro de 2011.

5 As Festas de "São João" é o termo utilizado popularmente nas festa /quadrilhas do ciclo junino.

${ }^{6}$ Da obra de Michel Maffesoli, Notas sobre a pós-modernidade: o lugar faz o elo. O autor aborda o poder dos espaços de celebração nas megalópoles, onde no sentido religioso do ter- 
mo são celebrados diversos cultos com forte coeficiente estético-ético. São as celebrações do corpo, do sexo, da imagem, da amizade, da "comédia", do esporte... (MAFFESOLI, 2004, p. $57)$.

${ }^{7}$ Trechos referentes à entrevista do Sr. Antony ao site da Prefeitura Municipal de Pacatuba, disponível em http://www.pacatuba.ce.gov.br.

${ }^{8}$ Organização da Sociedade Civil de Interesse Público ou OSCIP é um título fornecido pelo Ministério da Justiça do Brasil, cuja finalidade é facilitar o aparecimento de parcerias e convênios com todos os níveis de governo e órgãos públicos (federal, estadual e municipal) e permite que doações realizadas por empresas possam ser descontadas no imposto de renda. OSCIPs são ONGs criadas por iniciativa privada, que obtêm um certificado emitido pelo poder público federal ao comprovar o cumprimento de certos requisitos, especialmente aqueles derivados de normas de transparência administrativas. Em contrapartida, podem celebrar com o poder público os chamados termos de parceria, que são uma alternativa interessante aos convênios para ter maior agilidade e razoabilidade em prestar contas, disponível em http:// www.alfabrasil.org.br.

${ }^{9}$ A Lei Federal de Incentivo à Cultura (Lei no 8.313 de 23 de dezembro de 1991), conhecida também por Lei Rouanet, é a lei que institui politicas públicas para a cultura nacional, como o PRONAC - Programa Nacional de Apoio à Cultura, disponível em http://www.planalto.gov.br.

Maryvone Moura Gomes: Universidade Federal do Ceará, Fortaleza, CE, Brasil.

Email: maryvone@gmail.com

Link para o currículo Lattes: http://lattes.cnpq.br/3713902874688071

Christian Dennys Monteiro de Oliveira: Universidade Federal do Ceará, Fortaleza, CE, Brasil.

Email: cdennys@ufc.br

Link para o currículo Lattes: http://lattes.cnpq.br/6672867433887720

Data de submissão: 10 de junho de 2012

Data de recebimento de correções: 18 de junho de 2013

Data do aceite: 01 de julho de 2013

Avaliado anonimamente 